\title{
Imaging the ignition of dense, inhomogeneous liquid fuel sprays at elevated temperatures and pressures
}

\author{
M. Han ${ }^{1}$, R.L. Gordon ${ }^{1}$, M. Talei ${ }^{1}$, M.J. Brear ${ }^{1}$ and J.S. Lacey ${ }^{2}$ \\ ${ }^{1}$ Department of Mechanical Engineering \\ The University of Melbourne, Melbourne, Victoria, 3010, Australia \\ 2 Department of Mechanical Engineering \\ KU Leuven, Leuven, 3000, Belgium
}

\begin{abstract}
This paper investigates the forced ignition of inhomogeneous, dense liquid fuel sprays. The fuel spray is pure n-Heptane, injected with a prototype gasoline direct injector designed by Delphi for the Engine Combustion Network's Spray G research. This spray is ignited by a laser spark, delivered by a custombuilt high precision laser traverse system. The spray ignition process is recorded with a high-repetition rate schlieren imaging system. The impact of changes in chamber pressure and temperature on ignition probability statistics are investigated. Ignition probability is reduced by increasing chamber pressure and promoted by increasing chamber temperature. At a constant laminar flame speed, the impact of chamber temperature increase is greater than that of chamber pressure increase.
\end{abstract}

\section{Keywords}

Inhomogeneous dense sprays; Constant volume chamber; Laser ignition; Schlieren imaging; ECN Spray G

\section{Introduction}

Spray ignition is one of the fundamental problems in combustion science and has a wide application in modern power and transport systems [1]. A successful ignition process includes flame kernel generation, kernel growth and flame stabilization. The coupled complexity of spray atomization and turbulent combustion has impeded a full understanding of spray ignition phenomenon, and this is compounded by the majority of experimental studies being conducted at Normal Temperature and Pressure. These conditions are insufficient for extrapolation to engine-relevant pressures and temperatures.

Research on non-premixed spray ignition in recent years has been extensively reviewed by Mastorakos [1-3]. The important concept of ignition probability, $\mathrm{P}_{\mathrm{ign}}$, is developed by Ahmed et $a l$. to define the inhomogeneous spray ignition statistical behaviour $[4,5]$. Spray ignition was categorised into three modes: kernel generation, flame growth, and burner-scale flame establishment. Marchione et al. examined the ignition process of a n-Heptane spray generated by a hollow-cone pressure atomizer in a flow liquid-fueled burner [6]. Oliveira et al. studied the ignition probability of different fuels at various equivalence ratios, temperatures, and flow velocities [7]. However, these systematic spray ignition studies were mainly conducted at the atmospheric pressure.

Direct Injection Spark Ignition (DISI) engine can offer improvements in fuel economy by unthrottled load control, and allows for higher compression ratios due to the higher knock resistance induced by greater charge cooling $[8,9]$. However, the short time duration between the injection and spark event creates highly stratified mixtures near the spark [8]. Therefore, optical spray ignition research at elevated pressure has mainly been conducted in optical engines designed for DISI engines $[8,10]$. This experimental environment couples bulk fluid motion, turbulence, and geometric effects, making it very difficult to resolve the controlling physics of any particular phenomenon.

To address these experimental limitations, Constant Volume Chambers (CVCs) have been used to conduct systematic, quasi steady-state, optical fuel spray studies at elevated pressures and temperatures $[9,11,12]$. To investigate fuel spray ignition at these conditions, a CVC has been modified for laser spark ignition studies. The suitability of this ignition CVC for dense, inhomogeneous, fuel spray ignition will be demonstrated in this paper. The image sequences will be used to describe the ignition process. The effects of chamber pressure and temperature on ignition performance will be evaluated using ignition probability statistics. The provided dataset can also be used as validation data for modelling DISI engines.

\section{Experimental Method}

\section{Experimental setup}

The ignition CVC is shown in Figure 1, and is modified from a non-reacting fuel spray research facility $[9,11,12]$. The CVC has three $90 \mathrm{~mm}$ diameter, $45 \mathrm{~mm}$ thick fused-silica windows. A symmetric, 8-hole Delphi direct fuel injector is used, which was designed for the Engine Combustion Network (ECN) Spray G investigations [13]. It is mounted on the top side of the CVC, covered by circulating coolant. For this study, the Spray G injector is adjusted such that one plume is closest to the imaging camera, centered in the z-direction. The trajectory of this plume is in the negative y-direction along the imaging center-line, angled towards the camera.

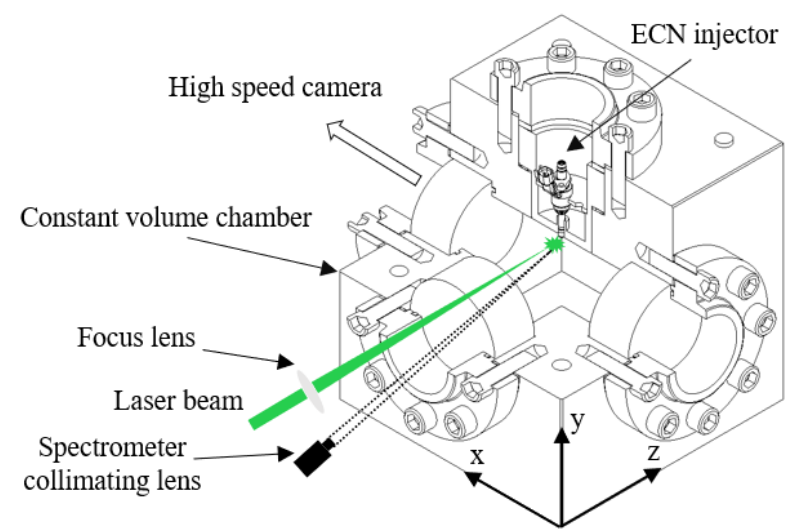

Figure 1. Schematic of the spray laser ignition rig.

The $\mathrm{n}$-Heptane fuel is delivered via a fuel rail maintained at 50 bar by compressed nitrogen. The injection duration of all exper- 
iments in this study is $2 \mathrm{~ms}$. The chamber pressure is maintained by compressed air, and the chamber temperature is controlled by four cartridge heaters mounted in the metal of the corners of the CVC. The experimental conditions are summarized in Table 1 . The variation of chamber pressure is within \pm 0.1 bar and variation of chamber temperature is within $\pm 2 \mathrm{~K}$ for all experiments. The fuel temperature is $298 \mathrm{~K}$ for the $T_{\text {chamber }}=298$ $\mathrm{K}$, and $323 \mathrm{~K}$ when $T_{\text {chamber }}=400 \mathrm{~K}$. The variation of the fuel temperature is less than $\pm 2 \mathrm{~K}$.

\begin{tabular}{rr}
\hline Fuel & n-Heptane \\
Chamber pressure (bar) & 2,8 \\
Chamber temperature (K) & 298,400 \\
Fuel rail pressure (bar) & 50 \\
Injection duration (ms) & 2 \\
Spark time after injection (ms) & 1.1 \\
\hline
\end{tabular}

Table 1. Key parameters of spray ignition.

\section{Laser ignition system and imaging system}

A key modification in the ignition CVC rig is the introduction of an external 2-axis traverse for the delivery of a focused laser, which creates a spark inside the chamber. This spark can be traversed in the y-direction (vertically along the axis of the injector), or laterally along the $\mathrm{x}$-direction towards the observation window/camera. In the z-direction, the laser is focused to create an induced breakdown at the centerline of the rig/spray, which coincides with the edge of the center spray plume closest to the camera.

The laser spark traverse is shown in Figure 2. The laser spark is generated from the focused pulse of a frequency-doubled Brilliant EaZy Nd:YAG laser, which delivers approximately $95 \mathrm{~mJ} /$ pulse. It is triggered $1.1 \mathrm{~ms}$ after the start of injection. The spark location can be traversed with a precision of $20 \mathrm{mi}-$ cron. A Galilean beam expander with magnification ratio of 2.33 is used to enlarge the beam diameter to reduce the possibility of damage to the fused silica window, and to reduce the beam waist of the focal point. The beam is focused with a circular $250 \mathrm{~mm}$ convex lens, as shown in Figure 1.

The $\mathrm{z}$-axis variability of the spark location is determined from imaging 50 laser shots, with a maximum discrepancy within \pm 1 $\mathrm{mm}$. The y-axis laser spark position is approximately half the spray penetration length at sparking moment. The $\mathrm{x}$-axis position is aligned with the spray edge closest to the camera. This $\mathrm{X} / \mathrm{Y}$ location is different for each case, shown in Table 2. The uncertainty of the spark position in $\mathrm{x}$ - and $\mathrm{y}$-coordinates relative to the injector tip is less than $\pm 1 \mathrm{~mm}$, and remains constant during the experiment. A photodiode is used to monitor the laser shot-to-shot energy variation, and the maximum normalized variance of the recorded photodiode voltage in one sparking position is $3.7 \%$.

Schlieren images are recorded with a Photron SA1.1 CMOS camera at 20,000 fps. The schlieren system is arranged in a $\mathrm{z}$ configuration and is illuminated with a Visual Instrumentation 900170W strobed ultra-bright LED light synchronized with the high-speed camera. The LED exposure time is $5 \mu s$. The spray boundary is determined from schlieren images using a Prewitt operator for edge detection.

\section{Results and discussion}

\section{Successful ignition process at different chamber condition}

Representative successful ignition sequences at different chamber conditions are shown in Figure 3. The spark is generated,

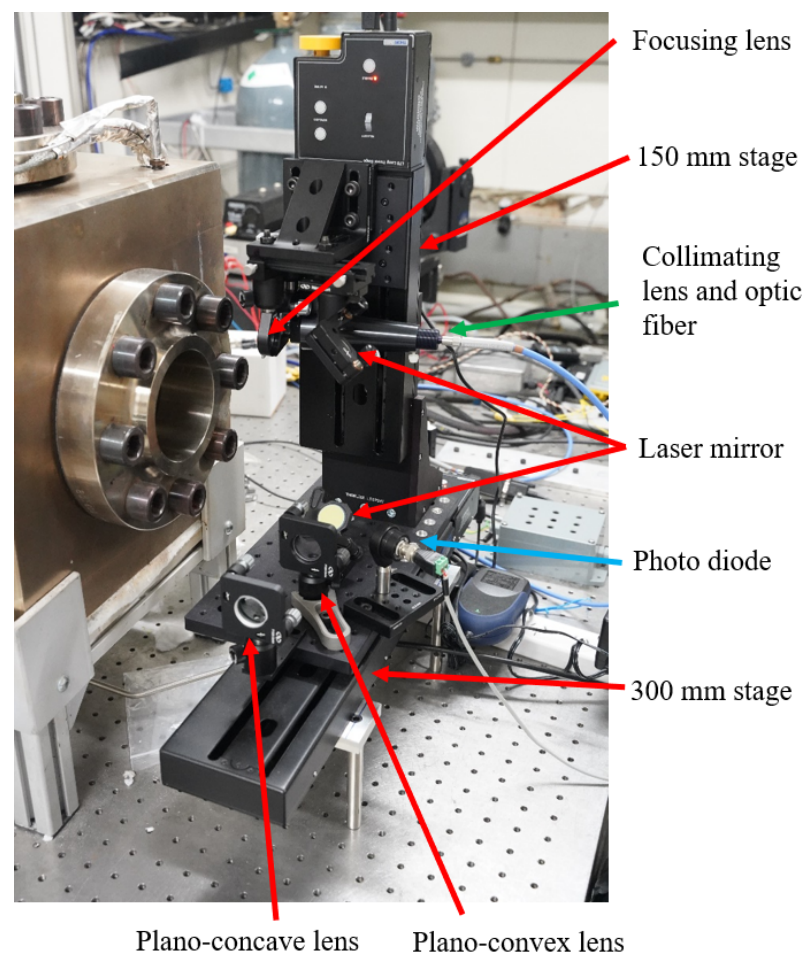

Figure 2. Laser traverse platform.

and in the successful ignition cases, the initial flame kernel is not convected downstream by the spray plume, but remains centered around its original position. Later, the flame kernel created in this area begins to spread in both horizontal and vertical directions, following the spray motion. Finally, the flame occupies almost the entire plume, and begins to ignite neighbouring plumes. The injector closes at $900 \mu \mathrm{s}$ after sparking, $2 \mathrm{~ms}$ after start of injection. Prior to this, the injected fuel blocks the imaged density gradients made by the heat release of combustion, rendering the reacting kernel edge difficult to resolve from the acquired images during this period.

A vertical spray edge speed is defined at the spark instant, $1.1 \mathrm{~ms}$ after injection. It is determined from the gradient of a curve fitted to the ensemble-averaged leading edge of the spray versus time for the non-sparked experiments. The values are presented in Table 2. Increased chamber pressure results in the spray penetration length being reduced, qualitatively shown in Figure 4, and in lower vertical spray edge speeds. This is likely due to the higher air density and drag force on the droplets. Elevating chamber temperature does not have a significant impact on penetration trajectory versus time, so these curves are not shown, for simplicity. However, as can be seen in the final frames of Fig. 3 this results in the final flame area being significantly larger than room temperature conditions, and broader lateral flame spread. This can be observed in Figure $3 \mathrm{a}$ versus $3 \mathrm{c}$ or Figure $3 \mathrm{~b}$ versus $3 \mathrm{~d}$. The observed effects of elevating chamber temperature on the spray ignition are likely due to reduced droplet size, and enhanced evaporation rate. The successful ignition data follow the same trajectory as the non-reacting cases, indicating that the spark and combustion processes are not disturbing the leading edge of the spray.

Table 2 also presents the laminar flame speeds of a stoichiometric premixed gaseous $\mathrm{n}$-Heptane/air flame at the given chamber pressures and temperatures, computed with Chemkin using the LLNL chemical kinetic mechanism [14]. The 2 bar, $298 \mathrm{~K}$ case and the 8 bar, $400 \mathrm{~K}$ case are chosen such that the laminar flame 


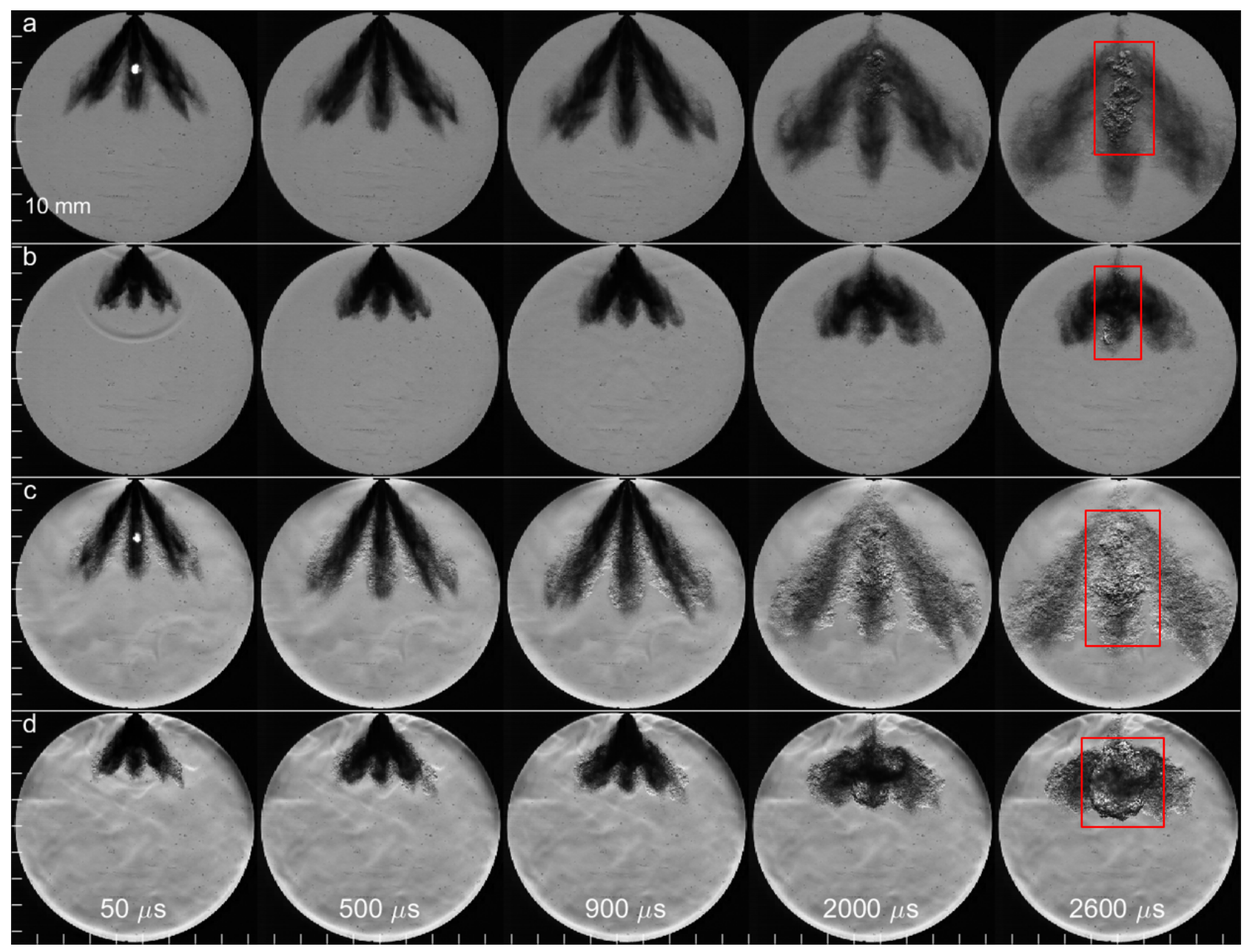

Figure 3. Individual realisations of successful ignition: (a) 2 bar, $298 \mathrm{~K}$; (b) 8 bar, $298 \mathrm{~K}$; (c) 2 bar, $400 \mathrm{~K}$; (d) 8 bar, $400 \mathrm{~K}$. Time is indicated after start of laser sparking. The step of the horizontal and vertical scale marks is $10 \mathrm{~mm}$. Approximate regions of combustion are indicated with a red rectangle at $2600 \mu s$.

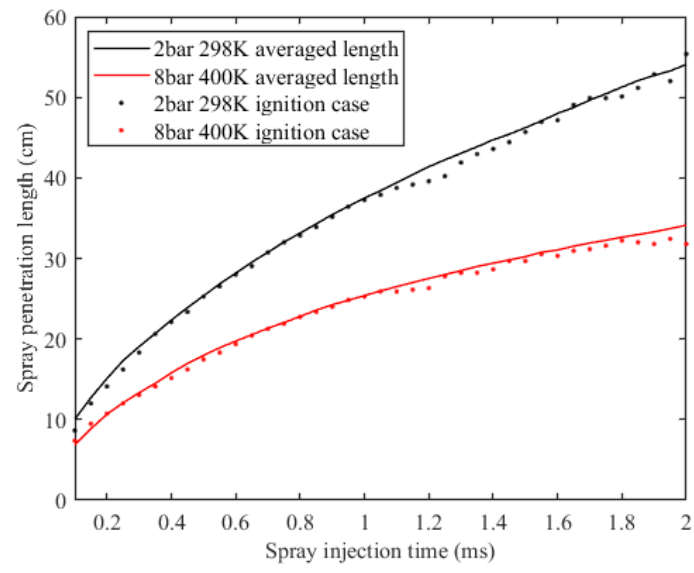

Figure 4. Penetration length versus injection time $(0.1 \mathrm{~ms}$ to 2 $\mathrm{ms})$. Solid lines: leading spray edge location for non-reacting cases, ensemble-averaged from 30 instances; solid dots: leading spray edge location for the single realisation of the successful ignition cases from Figure 3.

speeds are similar. The speed increase due to increased temperature is countered by the speed decrease due to increased pressure. This permits a comparison between the competing effects of chamber temperature and pressure in Figure $3 \mathrm{a}$ and Figure 3d.

\begin{tabular}{rrrrr}
\hline $\begin{array}{r}\text { Pres. } \\
\text { bar }\end{array}$ & $\begin{array}{r}\text { Temp } \\
\mathrm{K}\end{array}$ & $\begin{array}{r}S_{L} \\
\mathrm{~cm} / \mathrm{s}\end{array}$ & $\begin{array}{r}\text { Edge speed } \\
\mathrm{m} / \mathrm{s}\end{array}$ & $\begin{array}{r}\mathrm{X} / \mathrm{Y} \text { loc } \\
\mathrm{mm}\end{array}$ \\
\hline 2 & 298 & 33.0 & 20.9 & $20.5 / 20$ \\
2 & 400 & 54.0 & 20.8 & $22 / 21$ \\
8 & 298 & 21.2 & 12.3 & $15 / 13$ \\
8 & 400 & 34.8 & 12.3 & $15 / 13$ \\
\hline
\end{tabular}

Table 2. For each case, laminar flame speed $\left(S_{L}\right)$, leading spray edge vertical propagation speed ("Edge Speed") at the time of the laser spark $(1.1 \mathrm{~ms})$, and $\mathrm{X}$ and $\mathrm{Y}$ location of the laser spark.

\section{Ignition probability based on schlieren images}

The stochasticity of spray injection process means that a statistical summary of repeat ignition trials is more relevant to indicate the effect of chamber condition on successful ignition. Ignition probability is used as the criterion, defined in $[4,5]$ as

$$
\mathrm{P}_{\text {ign }}=\frac{J}{N}
$$

where $\mathrm{N}$ is the number of overall trials and $\mathrm{J}$ is the number of 
successful ignitions.

At least 15 successful laser shots are conducted for statistical analysis in each chamber condition. As summarized in Table 3, the ignition probability is dramatically reduced when increasing chamber pressure at room temperature, indicating the negative effect of chamber pressure on successful ignition. The potential reasons are larger droplet sizes, smaller flame speeds, and less fuel distribution around the sparking volume. The ignition probability also shows that increasing ambient temperature results in improved ignition performance.

\begin{tabular}{rrr}
\hline $\begin{array}{r}\text { Pressure } \\
\text { bar }\end{array}$ & $\begin{array}{r}\text { Temperature } \\
\text { K }\end{array}$ & $\begin{array}{r}\text { Probability } \\
\%\end{array}$ \\
\hline 2 & 298 & 75.0 \\
2 & 400 & 100.0 \\
8 & 298 & 13.3 \\
8 & 400 & 81.8 \\
\hline
\end{tabular}

Table 3. Statistical ignition probabilities and the corresponding sparking position away from the injector tip.

\section{Conclusion}

A Constant Volume Chamber (CVC) has been modified to permit fuel spray ignition studies. It is demonstrated to be suitable for dense spray ignition experiments at elevated chamber pressure and temperature. Schlieren imaging has been used for spray injection visualisation, laser spark positioning, and ignition event visualisation. Ignition probability is determined for all cases. Increasing chamber pressure decreased the ignition probability, but elevating chamber temperature increased the ignition probability. At similar laminar flame speeds, the impact of increasing chamber temperature on spray ignition probability is larger than that of increasing chamber pressure. This preliminary investigation demonstrates that fluid dynamic and evaporation processes have a significant influence on ignition and flame propagation.

\section{Acknowledgements}

Mr. Han acknowledges the support of the University of Melbourne through the IRRTF program. Mohsen Talei was supported by the Australian Research Council (ARC) through the DECRA Fellowship (DE180100416). This work is part of the Holistic Approach of Spray Injection through a Generalized Multi-phase Framework (HAoS) project, which is supported by the EU as part of the MSCA-ITN-2015-ETN - Marie Skodowska-Curie Innovative Training Networks (ITN-ETN) program, grant agreement 675676 .

\section{References}

[1] Mastorakos E. (2017). Forced ignition of turbulent spray flames. Proceedings of the Combustion Institute, 36(2), 2367-2383 (DOI:10.1016/j.proci.2016.08.044).

[2] Mastorakos E. (2009). Spark ignition of turbulent non-premixed flames: experiments and simulations. AIP Conference Proceedings, 1190(1), 63-67 (DOI: 10.1063/1.3290169).

[3] Mastorakos E. (2009). Ignition of turbulent non-premixed flames. Progress in Energy and Combustion Science, 35(1), 57-97 (DOI: 10.1016/j.pecs.2008.07.002).

[4] Ahmed SF, Mastorakos E. (2006). Spark ignition of lifted turbulent jet flames. Combustion and Flame, 146(1), 215231 (DOI: 10.1016/j.combustflame.2006.03.007).
[5] Ahmed SF, Balachandran R, Marchione T, Mastorakos E. (2007). Spark ignition of turbulent nonpremixed bluff-body flames. Combustion and Flame, 151(1), 366-385 (DOI: 10.1016/j.combustflame.2007.06.012).

[6] Marchione T, Ahmed SF, Mastorakos E. (2009). Ignition of turbulent swirling n-heptane spray flames using single and multiple sparks. Combustion and Flame, 156(1), 166-180 (DOI: 10.1016/j.combustflame.2008.10.003).

[7] de Oliveira PM, Allison PM, Mastorakos E. (2017) Forced ignition of dispersions of liquid fuel in turbulent air flow. in 55th AIAA Aerospace Sciences Meeting. American Institute of Aeronautics and Astronautics, Grapevine, Texas.

[8] Peterson B, Reuss DL, Sick V. (2011). High-speed imaging analysis of misfires in a spray-guided direct injection engine. Proceedings of the Combustion Institute, 33(2), 30893096 (DOI: 10.1016/j.proci.2010.07.079).

[9] Lacey JS, Poursadegh F, Brear MJ, Gordon RL, Petersen P, Lakey C, Butcher B, Ryan S. (2017). Generalizing the behavior of flash-boiling, plume interaction and spray collapse for multi-hole, direct injection. Fuel, 200, 345-356 (DOI: 10.1016/j.fuel.2017.03.057).

[10] Peterson B, Reuss DL, Sick V. (2014). On the ignition and flame development in a spray-guided direct-injection sparkignition engine. Combustion and Flame, 161(1), 240-255 (DOI: 10.1016/j.combustflame.2013.08.019).

[11] Poursadegh, F, Lacey, JS, Brear MJ, Gordon RL. (2017). On the Fuel Spray Transition to Dense Fluid Mixing at Reciprocating Engine Conditions. Energy \& Fuels, 31(6), 6445-6454 (DOI: 10.1021/acs.energyfuels.7b00050).

[12] Poursadegh F, Lacey JS, Brear MJ, Gordon RL., Petersen P, Lakey C, Butcher B, Ryan S, Kramer U. (2018). On the phase and structural variability of directly injected propane at spark ignition engine conditions. Fuel, 222, 294-306 (DOI: 10.1016/j.fuel.2018.02.137).

[13] "Engine combustion network", http://www.sandia.gov/ecn/, Accessed: 16-07-2020, 2020.

[14] Mehl M, Pitz WJ, Westbrook CK, Curran HJ. (2011). Kinetic modeling of gasoline surrogate components and mixtures under engine conditions. Proceedings of the Combustion Institute, 33(1), 193-200 (DOI: 10.1016/j.proci.2010.05.027). 


\section{University Library}

\section{- M M I N E R VA A gateway to Melbourne's research publications}

Minerva Access is the Institutional Repository of The University of Melbourne

Author/s:

Han, M;Gordon, R;Talei, M;Brear, M;Lacey, J

Title:

Imaging the ignition of dense, inhomogenous liquid fuel sprays at elevated temperatures and pressures

Date:

2020

\section{Citation:}

Han, M., Gordon, R., Talei, M., Brear, M. \& Lacey, J. (2020). Imaging the ignition of dense, inhomogenous liquid fuel sprays at elevated temperatures and pressures. Proceedings of the 22nd Australasian Fluid Mechanics Conference AFMC2020, The University of Queensland. https://doi.org/10.14264/d66d1aa.

Persistent Link:

http://hdl.handle.net/11343/275198 